\title{
A Review- Role of Mobile Application for Medical Services
}

\author{
Miss. Naina S Thorat ${ }^{1}$, Dr. R. V Kulkarni ${ }^{2}$ \\ ${ }^{1}$ Department of Computer Science, ${ }^{2}$ Department of Commerce and Management \\ 1 Sadguru Gadage Maharaj College, Karad, Maharashtra, India \\ ${ }^{2}$ Chhatrapati Shahu Institute of Business Education and Research Center Kolhapur, Maharashtra, India
}

\begin{abstract}
Organised By:
Management Department, Chhatrapati Shahu Institute of Business Education and Research, Kolhapur, Maharashtra

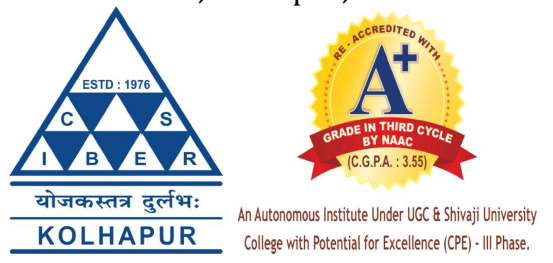

How to cite this paper: Miss. Naina S Thorat | Dr. R. V Kulkarni "A ReviewRole of Mobile Application for Medical Services" Published in International Journal of Trend in Scientific Research and Development (ijtsrd), ISSN: 24566470, Special Issue |

Fostering

Innovation,

Integration and Inclusion Through Interdisciplinary

Practices in

Management, March

2019, pp.43-45, URL:

https://www.ijtsrd.com/papers/ijtsrd2 3060.pdf

\section{ABSTRACT}

In advanced mobile communications and portable computation devices are now combined in handheld devices called "smart mobile phones, IPADs, Tablet PC", which are also capable of running third-party software. The number of smart mobile phones users is growing rapidly, including among healthcare professionals. The purpose of this study was to classify smart mobile phones based healthcare technologies as discussed in academic literature according to their functionalities, services and summarize articles in each category.

Many medical applications for smart mobile phones have been developed and widely used by health professionals, doctors, consultant and patients. The use of smart phones is getting more attention in healthcare and medical services day by day. Medical service provider applications make smart mobile phones useful tools in the practice of evidence-based medicine at the point of care, in addition to their use in mobile clinical communication with an correct references. Also, smart mobile phones can play a very important role in patient education, disease self-management, and remote monitoring of patients.

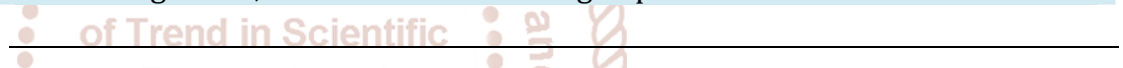

KEYWORDS: OPD-Out Door Patients, IPD-In Door Patients, HSR-Health Service Research Development

\section{INTRODUCTION}

Medical services or mobile services are the combination of to make user friendly relationship between patients and doctors. There are lots of barriers and problems are faced to providing health service to the patients. In India there is a provide the awareness of medical services .It is one kind of challenges, to providing services, investigation, quality, cost and key features. The researcher provides the proper outcome, service quality, service cost for populations.

The health service research (HSR) held to provide the medical facilities. The goal of HSR is to provide information to improve health of patients or citizens. HSR is a multidisciplinary field that moves beyond basic and applied research, drawing on all the health professions and on many academic disciplines, including biostatistics, epidemiology, health economics, medicine, nursing, operations research, psychology, and sociology.

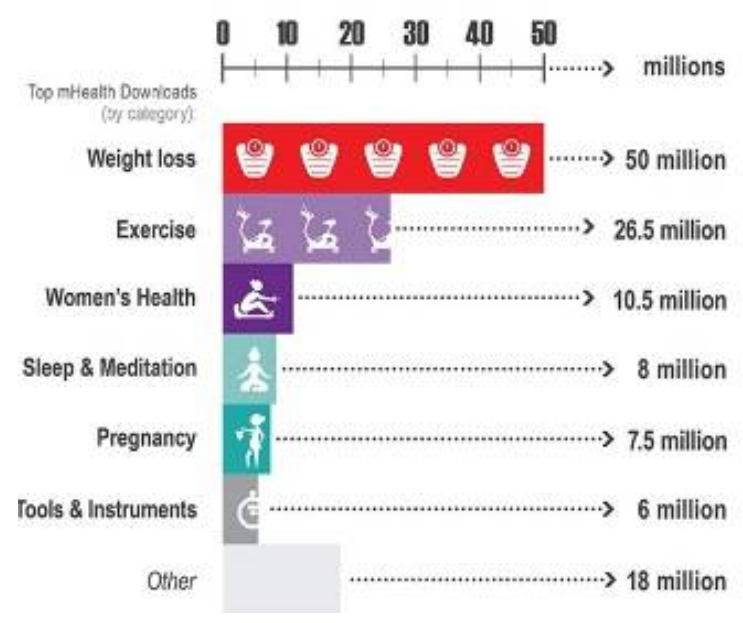


In the United States, the National Healthcare Quality Report, ${ }^{11}$ National Healthcare Disparities Report, ${ }^{12}$ and Healthy People Year $2010^{13}$ exemplify our capacity for monitoring quality and assessing change. As per the previous researcher to research the health services to the patients, or survey it is beneficial for the maintain security or reduce the paper work.

Mobile health app are to be work on the parameters of patient report. Mobile health app is beneficial for the doctors because:- $40 \%$ doctors believe mobile technology can reduce the number of visits to the clinic. 93\% physician accepts that mobile can improve patient's health as well as it helps to provide the required details at emergency.

Goals for Health Services and Patient:- As per pre scenario there is a to maintain the patient doctor relationship. There was a one kind of the good citizen responsibility.

Patient safety:- It will be provide the fast service to the patients at the time of emergency. The patient get the detail knowledge about the their medical situation.

Effectiveness:- Mobile app are helped to the patients or relatives to get all report or parameters regarding the decease or any medical service detail which is provided by hospital or doctors.

Patient centered:- All medical services are for the user or patients, patient is the center point of medical services or health services. It all about the patient safety.

Equity:- Any health service to maintain the quality of health services.

\section{MOBILE MEDICAL APPLICATION}

Mobile health app or medical services apps are targeting to a patient monitoring, documentation and service intimations are increasingly useful to every user which is related to accessing or using these smart phone mobile phone app. Healthcare apps can radically improve the ease access and speed with which healthcare professionals can access, analyze, and respond to clinical data and reference information. Smart mobile phones or touch screen devices also aide the clinicians by providing the capability of visual representation and manipulation of reference material and parameter based reports. General architecture of health monitoring application or health service applications consists of three separate tiers. The first tier consists of sensors devices that monitor vital signs of human body. The second tier includes the devices at the end user such as IPDAs, Tablet PC or smart mobile phones. These devices act as mediators that communicate the data between first tier and the third tier. At the third tier, there are actually servers the platform to perform actual functionality and provide database operation facilities to the number of applications.

Recent years in India it has seen an increased adoption of smart phones by healthcare professionals. The smart phone is a new technology that combines mobile communication and computation in a handheld-sized device like Tablet, IPADs, facilitating mobile computing at the point of care. The main objective of this study is to classify the Smartphonebased healthcare technologies in the literature according to their functionalities and summarize them in each category.
We presenting a systematic literature review in this regard. To the best of our knowledge, this study is the first study for classifying and summarizing health service applications for smart mobile phones in a systematic literature review format.

The healthcare system is highly mobile in nature, involving multiple clinical locations such as clinics, IPD patient wards, OPD patient services, emergency departments, operating theaters, intensive care units (ICUs), Test laboratories, etc. As such, working in the healthcare system requires extensive mobility of healthcare professionals as well as communication and collaboration among different individuals, including their colleagues and patients. Healthcare professionals mainly used pagers for mobile communication until the wide availability of cell phones in 1990s

The Advantages of Mobile App for Healthcare Industry:1. Medical Service Apps for Doctors and Medical staff:As per studied scenario near about $93 \%$ doctors are using apps for improving knowledge about health condition of their patients. It helps to view your all report through the app to take quick decision in emergency cases.

2. Medical services apps are beneficial for Patients:The patients are receive the most benefits of the medical service apps whether it is quick appointment with doctors, finding an appropriate specialist with on experience, view the medical test reports from labs online and so on.

3. Reduce the risk of wrong Diagnosis:-

In earlier days we heard a lot of cases where the patients having a dangerous an diagnostic approach, at that time number of medical health apps useful for receive an accurate report of the patients health condition and it helps to prescribe the most accurate medicine with write dosage.

\section{Reducing Medical Bill and Expenses:-}

It it one of the important advantage of medical apps to reduces medical bills and expenses. It help to reduce time to visit hospital for appointment, collection of reports etc.

\section{Easy Payment Bills:-}

It reducing queue to pay bill, it is highly secure to pay amount as well as if you forget to make a payment you will get notifications and reminder to do necessary.

\section{REVIEW OF LITERATURE}

For studied before scenario mobile health apps are the use of wireless communication devices to support public health and clinical practice. The purpose of mobile app is to rapidly to share health data at any time anywhere, patients can self monitor, and access their full record.

In(2007)- Researcher demonstrate usefulness queuing model providing guidance to patient panel size.[1]

In (2008)- Researcher describe the daily patient treatment and discussion on paper to reduce delay. [2]

International journal these paper representing the scheduling system of outdoor patients and consulting configuration. [3] 
International Journal of Trend in Scientific Research and Development (IJTSRD) @ www.ijtsrd.com eISSN: 2456-6470

This book represents involvement of information technology in all health care related sectors in United States.[4]

In (2011)- In international journal of computer science, shows the multi-agent environment to provide better quality service on java platform. The researcher or developer maintain the patient doctor meeting schedule. [5]

He make the strong relationship between outdoor patients and doctors behind the consult with a particular doctors. [6]

The researcher representing the classification, sequencing, scheduling, under new classification. [7]

In this article researcher describe about computer based electronic information system to build and maintain a patient database for analysis of data and to facilitate evidence-based decision making process. [8]

In this article researcher research android based patient appointment scheduling and medicine collection system developed, it helps to rescheduling appointment and cancelation process of appointment. [9]

In these paper to study the concepts of time and motion study, monitoring outdoor patients waiting time. [10]

The researcher represent efficient queuing model for appointment system to give long wetting time in hospital. [11]

\section{CONCLUSION}

In real world OPD patients are facing number of significant problems like appointment, registration, searching OPD locations, finding medicals, way to visit and lengthy process for consulting with doctors. The researcher develops the mobile app model to provide better medical services to citizens.

The use of mobile health apps could improve patient experience, especially with regard to accessing health information, making physician-patient communication more convenient, ensuring transparency in medical charge, and ameliorating short-term outcomes. All of these may contribute to positive health outcomes. Therefore, we should encourage the adoption of mobile health apps in health care settings so as to improve patient experience.

\section{REFERENCES}

[1] Linda V. Green, Sergei Savin (2007): "Reducing Delays for Medical Appointments: A Queuing Approach", Operations Research, Volume 56, No. 6, ISSN 0030$364 X$

[2] Linda V. Green (2008): Using Operations Research to Reduce Delays for Healthcare

[3] Zhu Z. C., Heng B. H., Teow, K. L. (2009): "Simulation Study of the Optimal Appointment Number for Outpatient Clinics"

[4] Devon M. Herrick, Linda Gorman, John C. Goodman (2010): "Health Information Technology: Benefits and Problems"

[5] Srividya Bhat, Nandini S. Sidnal, Ravi S. Malashetty, Sunilkumar. S. Manvi (2011): "Intelligent Scheduling in Health Care Domain"

[6] C. Kavitha, A. Venkat Ramana, S. Sushma Raj(2012): "Embedded Management System for Out Patient Department" (IJESA), Volume 2, No.3, DOI : 10.5121/ijesa.2012.2305

[7] Hyun-Jung Oh, Thomas Ptaszkiewicz (2013): "Guidelines for Scheduling in Primary Care Under Different" Healthcare Systems Engineering, Volume 3, ISSN: 1948-8300 Patient Types and Stochastic Nurse and Provider Service Times"

[8] Ayanthi Saranga Jayawardena (2014): "The Electronic Hospital Information System Implemented at the District General Hospital

[9] Swabik Musa Abdulla Wani, Suresh Sankaranarayanan (2014): "Intelligent Mobile Hospital Appointment Scheduling and Medicine Collection", Volume 1 No. 02, ISSN: 2312-7694

[10] Pradipti Verma, Dr. Risha Saxena(2015): “An Effective Time Motion Study (Tms) On Opd Patients Of A Tertiary Care Hospital In September 2015 In Goa"

[11] Obulor R., Eke B. O. (2016): “Outpatient Queuing Model Development For Hospital Appointment System”, Scientific Engineering and Applied Science, Volume 2, Issue 4, ISSN 2395-3470

Copyright (C) 2019 by author(s) and International Journal of Trend in Scientific Research and Development

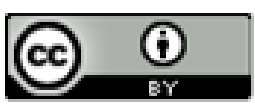
Journal. This is an Open Access article distributed under the terms of the Creative Commons Attribution License (CC BY 4.0) (http://creativecommons.org/licenses/by/4.0) 